Article

\title{
Public Access to Building Related Energy Data for Better Decision Making in Implementing Energy Efficiency Strategies: Legal Barriers and Technical Challenges
}

\author{
Susanne Geissler ${ }^{1, *}$, Alexandros G. Charalambides ${ }^{2}$ and Michael Hanratty ${ }^{3}$ \\ SERA Energy \& Resources, 1070 Vienna, Austria \\ Department, Cyprus University of Technology, 3036 Limassol, Cyprus; a.charalambides@cut.ac.cy \\ Energy Action, Dublin D12 WV91, Ireland; michael@energyaction.ie \\ * Correspondence: s.geissler@sera.global
}

Received: 22 April 2019; Accepted: 22 May 2019; Published: 27 May 2019

\begin{abstract}
The EU is committed to achieve ambitious energy efficiency and $\mathrm{CO}_{2}$ reduction targets. Regarding improving the energy performance of the building stock, detailed building related energy data made accessible by means of GIS are crucial. For this purpose, geo-referenced data from Energy Performance Certificates (EPC) according to the Energy Performance of Buildings Directive is of central importance, in order to facilitate decision-making about large-scale renovation projects and developing targeted products and services. The ENERFUND project developed a method and subsequently an internet based tool making use of EPC data from $13 \mathrm{EU}$ member states as well as other open-source data (such as renovation costs), thus clearly demonstrating the feasibility and usefulness of this approach. However, also technical challenges and legal barriers were encountered, such as a lack of data and varying data specifications depending on the national transposition of the European Directive, and different interpretation of specific clauses of the General Data Protection Regulation depending on EU member states' societal norms. Recommendations include the development of guidance notes to be issued by the responsible EU bodies to specify and harmonize data for mandatory public access, to ensure the effective implementation of energy efficiency and $\mathrm{CO}_{2}$ reduction policies in the EU's building sector.
\end{abstract}

Keywords: energy efficiency of building stock; renovation strategy; geodata; personal data; Energy Performance Certificate; Energy Performance of Buildings Directive (EPBD); General Data Protection Regulation (GDPR); ENERFUND

\section{Introduction}

This article describes the development of the ENERFUND tool as a reaction towards the fact that implementation of energy efficiency measures in the European building stock are severely lagging behind compared with the target values stipulated by European legislation. Weaknesses were identified on the basis of an evaluation of Directive 2010/31/EU (Energy Performance of Buildings Directive) and corresponding requirements were integrated by means of RL (EU) 2018/844, such as the development and implementation of a renovation strategy based on detailed milestones and with the aim of decarbonizing the building stock by 2050 (Art 2a RL (EU) 2018/844) [1].

In this context, the ENERFUND project aimed at using existing building related energy data taken from the Energy Performance Certificate (EPC) and making them publicly accessible by means of a geographical information system at the European level. It is the objective to facilitate targeted aggregation of renovation projects, and the development of new products and services in order 
to improve the energy efficiency of the building stock. During developing the ENERFUND tool, technical and legal barriers were encountered, analyzed, and suggestions were developed how to overcome them.

Legal barriers are explained by using the case of Austria, and discussed by including the case of Ireland. The paper closes with recommendations on how to address obstacles presently preventing authorities from granting open access to a wide range of EPC data in many EU member states, and thus hindering stakeholders in planning and implementing much needed measures for decarbonizing the European building stock.

In this chapter, the policy background with regard to the decarbonization of the building sector and the motivation for the ENERFUND project is presented in more detail in subchapter 1.1. It is followed by a subchapter explaining the European legislation influencing the development of the ENERFUND tool, that is on the one hand the enabling legislation on geodata and re-use of public sector information, and on the other hand limiting legislation on data protection. Chapter 1.2. lays the foundation to understand the main challenge with regard to making use of EPC data, namely the competing rights for public access to data and personal rights protection.

\subsection{Policy Background and Motivation: Decarbonizing the Building Sector}

Increasing the energy efficiency of the building stock and reducing greenhouse gas emissions is of the utmost importance in order to achieve the targets laid down in the Paris Agreement [2].

The public accessibility of geo-referenced, building related energy data, examined for its quality and explanatory power was well as for consistent coverage of existing buildings, is of great advantage for various target groups such as building owners, companies, financing organizations, politics, and civil society. These advantages include the identification of large-scale redevelopment projects and the preparation of project bundling to facilitate opportunities for financing energy efficiency improvements in existing buildings. Apart from its benefit for preparing investment projects, building related energy data is of major importance in energy spatial planning, which has gained much in importance with regard to the objective of decarbonizing the building stock: Decarbonizing shall be realized through an effective combination of energy saving and the replacement of fossil energy sources with renewables. Reliable electronic databases including geo-referenced data facilitating joint efforts in developing cost-effective rehabilitation projects, research, and developing new products and services are central to the sustainable implementation of energy and climate policy objectives of the Energy Union [3].

The most important EU legislation for the energy efficiency of buildings is the Energy Performance of Buildings Directive 2010/31/EU (recast) [4] as amended by Directive (EU) 2018/844 [1] (EPBD). According to EPBD, the Energy Performance Certificate (EPC) is the central document on the energy efficiency and $\mathrm{CO}_{2}$ emissions of a building. The EPC is a policy instrument serving two purposes: First, to prove energy efficiency objectives at building level for new buildings, and to inform tenants and buyers as well as the general public about the energy performance of buildings. Second, to also provide the database for planning, implementation, and the control of energy savings and $\mathrm{CO}_{2}$ reduction strategies and measures for the entire building sector.

EPCs have been issued since many years, based on the predecessor directives published in 1993 [5] and in 2002 [6]. Since then, there is the possibility to collect EPCs and also the input data required for the calculation of building energy efficiency, but to this day, there is no legal requirement at the EU level to do so. Implicitly, EPC databases became necessary as a consequence of the implementation of Article 18 EPBD prescribing an independent control system to ensure EPC quality, since an independent control system without electronic support can hardly be implemented effectively and at a reasonable cost. Amending Directive (EU) 2018/844 does not introduce any stipulations, either, but merely indicates in Article 10 (6a) and (6b) that databases may be set up to collect data on the measured or calculated energy consumption and that the data may be used for specific purposes when databases are available. The question of data collection and use for the implementation of the independent control system 
according to Article 18 EPBD and for the renovation strategy according to Article 2a EPBD is left to the member states, taking into account the European Union's guiding principles of subsidiarity and proportionality [7].

Therefore, the idea was to show this presumably huge richness in data at the European level, in order to make it accessible to the public and improve the decision-making basis for investments in energy efficiency of the building stock. To this end, the EU-funded project ENERFUND was launched in order to create a software application making EPC data and other open data sets publicly accessible by displaying them on a map and offering filtering and assessment options at the same time [8]. With this kind of open geo-referenced building related energy data, a first potential screening of third-party suppliers and companies would be significantly facilitated and a first step towards the implementation of large-scale building renovation projects would be successfully taken.

Today, after the completion of the funded project in April 2019, the ENERFUND tool contains more than eight million EPCs from 13 EU member states. However, quite some barriers have been encountered during the process of creating and populating the tool, which were only partly of a technical nature such as the need for geo-coding the EPCs due to not sufficiently precise information in the original documents. Much more severe problems are linked with the unwillingness of competent authorities to share data, and legal barriers, especially with limitations due to provisions of the General Data Protection Regulation (GDPR) [9] and the related range of interpretation. This compromises the potential related with public access to EPC data opened up by European legislation on environmental information [10], geospatial data [11], and open government data [12].

\subsection{Legal Foundation: Transparency of Public Administration and Protection of Personal Rights}

1.2.1. Transparency of Public Administration: Access to Environmental Information, Geodata, and Open Governmental Data

Directive 90/313/EEC of the Council of 7 June 1990 on the freedom of access to information on the environment initiated the process of making the public administration more transparent [13]. The currently valid version Directive 2003/4/EC (Environmental Information Directive) stipulates that environmentally relevant data must be accessible for the European Union's citizens, in order to strengthen environmental awareness and, as a consequence, to achieve environmental improvements. It is clearly emphasized that environmental information must be made accessible as far as possible and that information and communication technologies should be used for this purpose [10].

European Directives have to be transposed into national legislation, and in Austria, for example, the Environmental Information Directive is implemented by means of federal legislation and regional legislation in the responsibility of the nine Austrian provinces, the latter constituting the even more important part of the legal framework. For instance, the Austrian Province of Vienna specifies among others the following data explicitly as environmentally relevant and accessible in the respective Viennese law [14]:

- Basic data of real estate or parts of real estate:

(1) Size, location, and address;

(2) Topographical nature;

(3) Building stock, use, and technical facilities;

- Emission and immission values;

- Consumption of energy sources (especially solid fuels, oil, gas, electricity, and district heating).

The law precisely states in clause 11 paragraph 3 that data on size, location, address, condition, building stock, use, dedication, and usage restrictions of a property according to Viennese building legislation are permitted to be transferred to the Viennese Environmental Information System [15]. However, it is also emphasized that legislation to protect the rights of natural persons must be respected during processing personal data. 
Directive 2007/2/EC establishing an Infrastructure for Spatial Information in the European Community (INSPIRE) has its roots in environmental information legislation, being demonstrated in the recitals referring to the European Union's environmental policy and its aiming at a high level of environmental protection. It takes into account that geodata are an important source of information for the administration, as it is estimated that $80 \%$ of all administrative decisions are somehow linked with spatial information. Geodata contains spatial and time-related information about objects and facts. As a consequence of the INSPIRE Directive, the administration is not only active as an information processing body but also as an informing body. According to the Directive, geodata should be stored, accessed, and managed at the most appropriate level, coherently linked from different sources throughout the community and used by different users and for different applications. The aim of the INSPIRE Directive is to facilitate the interconnection of spatial data infrastructures and to ensure the interoperability of the managed and provided geodata, metadata, and spatial data services. According to article 4, it applies to spatial data sets that fulfill four conditions:

- They refer to an area in which a member state exercises sovereign powers;

- They are available in electronic form;

- They are in the hands of a public authority, have been drawn up by an authority, are administered by it, are managed by it, are covered by its public contract, are kept for it, or are available to third parties to whom network access is granted;

- And they concern one or more of the topics listed in Annex 1, 2, or 3 of the Directive.

Limitations will be legitimate if negative effects on specific areas can be expected, such as negative effects on the protection of personal data. However, it is also required that possible restrictions due to specific interests must be interpreted narrowly and have to be balanced against public interests.

Among others, the following topics must be made accessible and usable according to Annex 1 and Annex 3 of the INSPIRE-Directive:

- Geographical names: Names of areas, regions, towns, cities, suburbs, towns, or settlements and any geographical or topographical feature of public or historical interest.

- Administrative units: Local, regional, and national administrative units, which are separated by administrative boundaries.

- Addresses: Localization of properties based on address data, usually street name, house number, and postal code.

- Cadastral parcels: Areas determined by reference to the land register or equivalent directories.

- Building: Geographic location of buildings.

- Energy sources: Energy sources such as hydrocarbons, hydropower, bioenergy, solar, and wind energy, etc., possibly with depth and height information for the expansion of the energy source.

In Austria, geodata have been made accessible and usable by means of the governmental platform geoland.at [16].

The EU triggered the development in the Open Government Data (OGD) area also with Directive 2003/98/EC of 17 November 2003 on the re-use of public sector information, amended by Directive 2013/37/EU (PSI-Directive). The aim is to facilitate the re-use of public sector documents by entities for commercial and non-commercial purposes that differ from the original purpose of the public service contract under which the documents were created. In particular, it should encourage the creation of new information products and information services. Document is understood to mean any content, regardless of the form of the medium, and further use is understood to mean the use of the document for a purpose other than the original purpose of the public contract. The permissibility of the re-use of data is clearly defined by naming exemptions. For example, re-use of data will not be allowed if the creation is not covered by the public agency's mandate, if the data is not accessible for security and confidentiality purposes, if the data is third-party intellectual property, and other exceptions. 
Damm [17] (p. 65) refers to the Open Government Data Germany study, which defines the following requirements for the openness of administrative data [18]:

- Completeness;

- Primary sources;

- Temporal proximity;

- $\quad$ Easy access;

- Machine readability;

- Non-discrimination;

- Use of open standards;

- Licensing;

- Durability;

- Usage costs.

Excluded are personal data and other data requiring protection.

In a nutshell, the PSI-Directive has extended the scope from environmentally relevant information to all type of information, which can be re-used while respecting other legislation and security concerns. Both directives grant access to information on request, provided other legislation is not violated, whereby the need for compliance with data protection rules is specifically mentioned. In such a case, protected information is to be segregated from accessible information to be made available. However, this causes additional effort for the administration including the need for decision making, and therefore it is of utmost important to unambiguously clarify the need for segregation or anonymization, to avoid additional burden and to overcome reservations due to insecurity regarding the borderline between what is still within scope and what is not allowed anymore.

\subsubsection{Protection of Personal Rights: General Data Protection Regulation (GDPR)}

As early as 1995, Directive 95/46/EC on data protection was adopted [19]. The purpose of this Directive was, in particular, to remove barriers to the circulation of personal data relating to the establishment and functioning of the internal market and to ensure protection of personal rights at the same time. The establishment and functioning of the internal market is an important objective of the EU and results in economic and social integration leading to an increase in cross-border flows of personal data between all those involved in the economic and social life of the member states both public and private. It is therefore necessary to establish a consistent level of protection of the rights and freedoms of persons, in particular privacy, in the processing of personal data in the member states in order not to hinder the transmission of such data in the context of economic activities at the member states' level. However, Directive 95/46/EC could not prevent data protection in the EU from being handled differently. That is why the adoption of a European Regulation was necessary to ensure that uniform conditions have been created in all member states at the same time. The European General Data Protection Regulation (GDPR) was negotiated for several years, as a European Regulation must be implemented directly in member states without the possibilities to adapt the legal framework to national and regional conditions through transposition, as it is possible in the case of a European Directive. Finally, GDPR was adopted on 24 May 2016 after more than four years of negotiations. It has become evident, for example also through Edward Snowden's revelations that the digitization of all areas of the economy and life is leading to profound changes in international economic relations, and that therefore a European Regulation will be certainly needed if the personal rights of Europeans are to be truly preserved. Therefore, a single European standard should guarantee the free movement of personal data while safeguarding personal rights by establishing a uniform and high level of protection. The GDPR has been applicable since 25 May 2018 and follows Directive 95/46/EC, the objectives and principles of which continue to apply in accordance with recital 9 GDPR.

The GDPR provides that certain clauses can be specified by the member states' laws. These so-called opening clauses are important for the lawfulness of processing personal data according to article 6 
GDPR, especially regarding paragraph 1 point (c; processing is necessary for compliance with a legal obligation to which the controller is subject) and paragraph 1 point (e; processing is necessary for the performance of a task carried out in the public interest or in the exercise of official authority vested in the controller).

The protection of personal data serves the protection of personal rights, which is not only a highly ranked priority at the EU level, but also at the level of individual member states. The preservation of personal rights is the subject of the Convention for the Protection of Human Rights and Fundamental Freedoms (European Convention on Human Rights [20]) and the Charter of Fundamental Rights of the European Union [21]. In Austria, protection of personal rights has had a very high priority since the year 1811, enshrined in the Austrian General Civil Code adherent to innate rights [22] and right to privacy [23].

\section{The ENERFUND Approach}

This chapter describes the technical approach of developing the ENErgy Retrofit FUNDing rating (ENERFUND) tool, the challenges encountered and the results achieved.

\subsection{Technical Solution Envisaged}

The objective of the ENERFUND partners was to make use of open building related energy data and to create a quick evaluation tool to assist various target groups interested in screening the feasibility or usefulness of deep energy renovation of buildings and select those areas worth being examined in more depth. Therefore, identified open source databases with significant information about building energy performance were integrated in the ENERFUND tool on a user-friendly environment (http://app.enerfund.eu). The interface of the tool is a European map, which projects buildings and building units with colored dots, in accordance to their energy label and with several filtering options in order to assist the user to narrow down the range of screening buildings according to his or her preferences. At the home page of the ENERFUND tool, a drop-down list with all countries involved is used, in order to minimize the processing duration due to the large amount of integrated data. Additionally, after selecting the country of interest, the user can compare buildings and view detailed information regarding their energy performance along with other information for the building.

Furthermore, the tool provides the ENERFUND score per building or building unit, which is given on a percent scale and can be used to compare buildings of any country, since the score formula used is common for all countries. The ENERFUND score assists the decision-making process for the energy renovation of buildings and is based on a multi criteria analysis methodology. It is a result of an equation that uses eight main parameters, with different weight factors, which have been selected as key drivers for building energy retrofitting: Total area and energy saving potential (mandatory parameters), construction year, average building sale price, occupancy level, own contribution (to financing renovation), noise levels, and building ownership status. ENERFUND score uses data only from available in EU open-source databases, in order to maintain up to date data. In case that any of the above parameters are not available, default values have been used. The highest score that can be granted is 100 .

Finally, the user can produce a report based on the selection criteria. As a future development of the tool, in order to increase the tool's functionality and accuracy, user inputs regarding the selected buildings will be enabled [24].

In Figure 1, six screenshots present the step by step process on how to use the ENERFUND tool. The steps to be followed are:

(a) From https://app.enerfund.eu/, the user selects the country of interest.

(b) The current EPC rating of all the buildings in the said country in the form of colored dots are now displayed and the user can filter through the menu on the right of the screen. 
(c) Using the options in the right menu, the user can choose to display buildings based energy related data (i.e., only show buildings with an EPC rating of $F$ and $G$ ).

(d) The user can also choose other parameters, such as type of buildings or construction year.

(e) Once the user presses "Filter", only the buildings of interest are shown on the map, and the user can zoom in a specific region.

(f) By clicking on the colored dots and expanding the bottom menu, the user can see more detailed data per building.

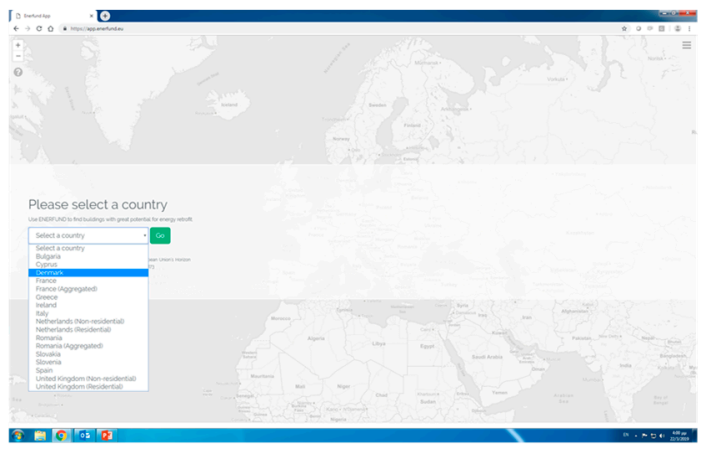

(a)

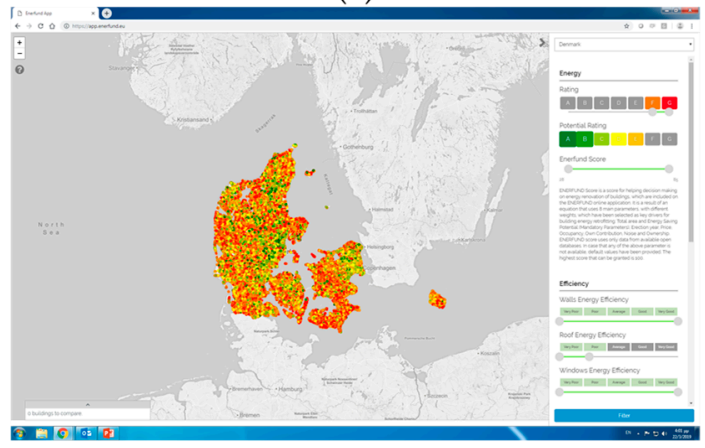

(c)

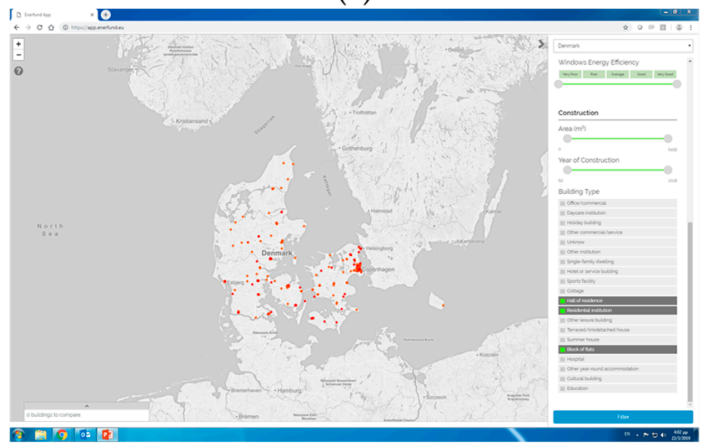

(e)

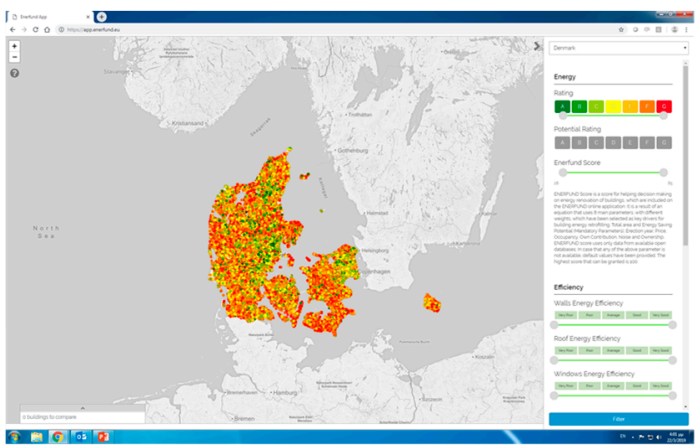

(b)

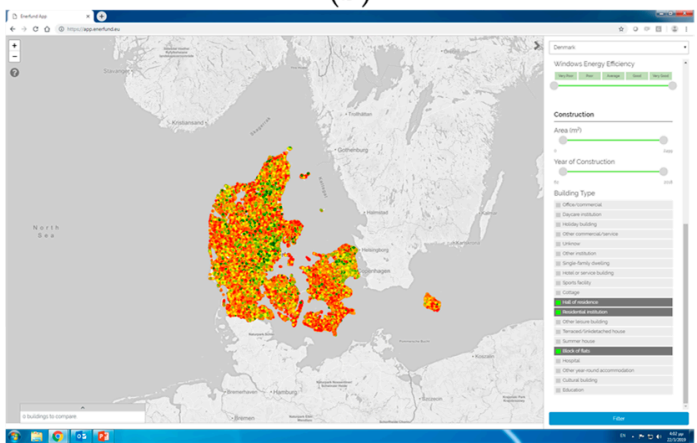

(d)

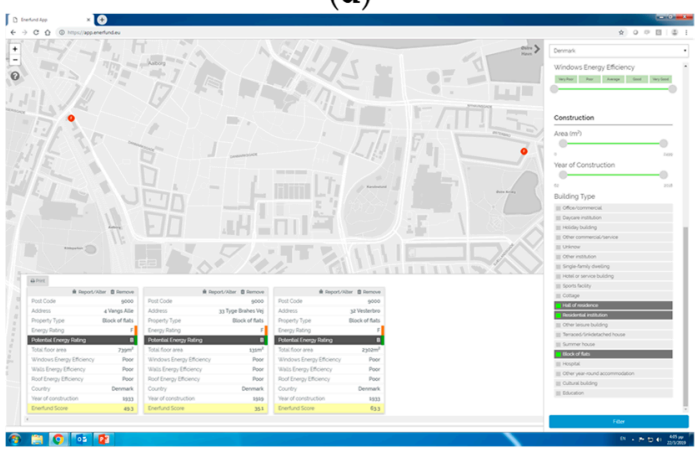

(f)

Figure 1. An example of how to use the ENERFUND tool.

In the example above, the user has chosen to study "Halls of Residence" and other similar buildings that have an F and G current EPC rating in Denmark and that can be renovated to an A or B rating. The user was interested in the Aalborg region, and three buildings matched the user's criteria. By comparing the three buildings, the ENERFUND score of one of those buildings was almost double of the other two, primarily due to its total floor area, and thus a higher impact can be achieved by its energy retrofit. 


\subsection{Data Source Energy Performance Certificate (EPC)}

The energy performance of buildings is determined according to the method specified by EPBD Annex 1, namely based on calculated or actual energy use, reflecting typical energy use for space heating, space cooling, domestic hot water, ventilation, built-in lighting, and other technical building systems. Only Sweden has used an approach exclusively based on actual energy use, all other member states have applied only calculated energy use or both approaches. Building energy performance is documented by the EPC, thus consisting of:

- The energy labeling, also called energy rating, and some key indicators about the building and its energy performance (such as address, area, climatic data, energy efficiency data in the form of several indicators, date of issue, and details concerning the company or person who issued the EPC);

- An attachment enclosing input-data needed for energy performance calculation and calculation results as such.

The EPC must be issued, presented and handed over to potential tenants and buyers, and under certain conditions, be displayed. Specific energy performance indicators must be included in real estate advertisements. The EPBD is a European Directive, meaning that member states transpose the Directive into national and/or regional legislation, making the necessary adaptations to adjust provisions to national and/or regional contexts. This not only applies to the content of the EPC as such, but also to the calculation method and thus to input data used for calculation, also. Especially with regard to existing buildings, a wide range of different approaches can be observed. Site inspection and collection of building specific data as well as use of default values based on building typologies is possible. More information is available in country reports as well as thematic reports published on the website of the Concerted Action EPBD https://epbd-ca.eu/.

The following description in Table 1 shows the minimum content as well as optional contents of the EPC as stipulated by the EPBD and illustrates which building related energy data the EPC may provide, thus demonstrating its essential relevance as a data source for the development, implementation and control of energy efficiency and $\mathrm{CO}_{2}$ reduction measures in buildings.

Table 1. Overview of minimum contents and optional contents of the Energy Performance Certificate (EPC).

\begin{tabular}{|c|c|c|}
\hline Type of Information & Minimum Contents of the EPC & Optional Contents of EPC \\
\hline $\begin{array}{l}\text { Parameters of energy efficiency } \\
\text { (article } 11 \text { paragraph } 1 \text { ) }\end{array}$ & $\begin{array}{l}\text { Overall energy performance of buildings and } \\
\text { parameters such as minimum requirements for } \\
\text { total energy efficiency to allow owners and } \\
\text { tenants of buildings or building units to compare } \\
\text { and assess their overall energy performance. }\end{array}$ & $\begin{array}{l}\text { Additional information such as } \\
\text { annual energy consumption, } \\
\text { percentage of energy from } \\
\text { renewable sources in the total } \\
\text { energy expenditure. }\end{array}$ \\
\hline $\begin{array}{l}\text { Recommendations for improving } \\
\text { energy efficiency (article } 11 \\
\text { paragraph } 2 \text { and } 3 \text { ) }\end{array}$ & $\begin{array}{l}\text { Recommendations for least-cost or cost-efficient } \\
\text { improvement of the energy efficiency of a } \\
\text { building or building unit; } \\
\text { recommendations must be technically feasible for } \\
\text { the specific building concerned. }\end{array}$ & $\begin{array}{l}\text { Estimation of the payback-period } \\
\text { or the cost advantages during the } \\
\text { operational life span. }\end{array}$ \\
\hline $\begin{array}{l}\text { Reference where to find detailed } \\
\text { information } \\
\text { (article } 11 \text { paragraph } 4 \text { ) }\end{array}$ & $\begin{array}{l}\text { Guideline (indication) where the owner or tenant } \\
\text { can obtain more detailed information concerning } \\
\text { the cost efficiency of recommendations contained } \\
\text { in the EPC; information regarding the steps to be } \\
\text { taken to implement these recommendations. }\end{array}$ & $\begin{array}{l}\text { Further information concerning } \\
\text { relevant aspects such as energy } \\
\text { audits or financial motivators or } \\
\text { other possibilities of financing. }\end{array}$ \\
\hline
\end{tabular}

According to article $18 \mathrm{EPBD}$, an independent quality control system for the quality assurance of EPCs has to be implemented. The EPBD does not require that an electronic EPC database be used as the basis for the establishment and operation of the independent control system. However, many member states or regions have chosen this approach because effective control is otherwise difficult to do cost effectively. It can only be guaranteed in satisfactory quality and with justifiable effort based on electronic collection of all calculation data, which is input data as well as calculation results. 
It also implies the possibility of using collected data for energy related purposes other than the control of EPCs.

The systematic collection of EPC data represents a potentially magnificent database to provide information for possible purchasers or tenants, for raising the population's awareness, for statistical analysis, for the development of large-scale renovation projects, product development, research projects, energy spatial planning, and, last but not least, for the evaluation and reporting to the EU. The spatial reference is of central importance, especially for the development of large-scale renovation projects and energy spatial planning. The majority of member states already operate EPC databases, which were established to implement the control system and some were opened for various target groups in order to increase the synergy effect in view of a greater transparency within the real estate market.

In Denmark, for example, everybody can get clear and easily understandable information about the energetic building condition by entering the address of the house in question on the Danish Energy Agency's internet platform (see Figure 2) and downloading the EPC. In addition, information about other buildings is available in order to allow for comparison of energy performance.

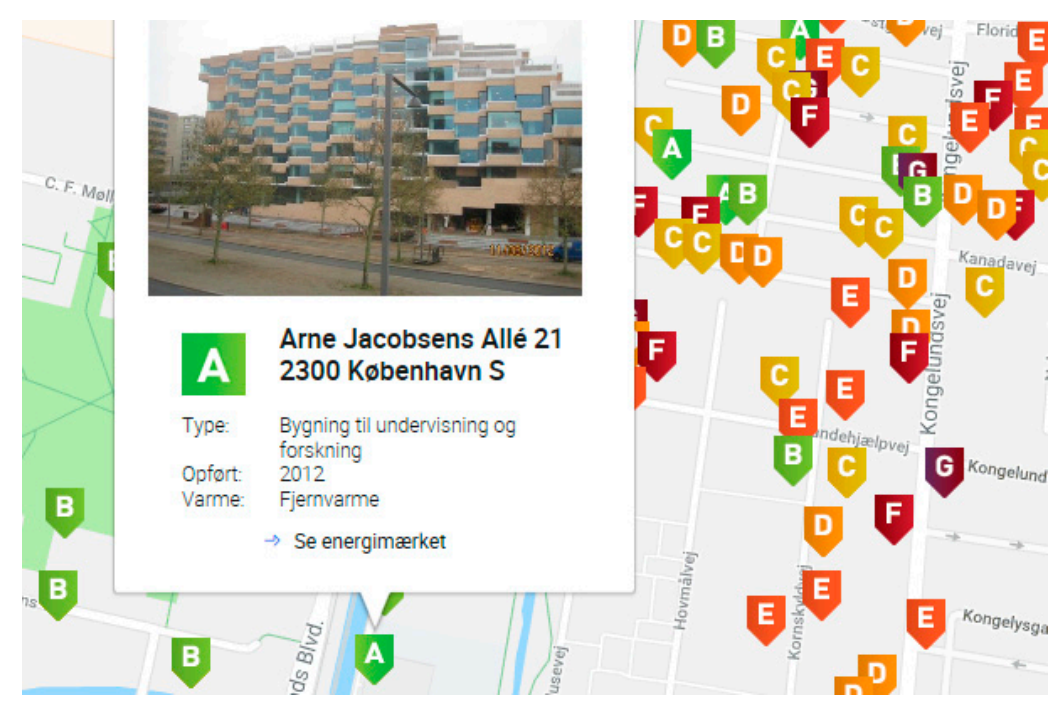

Figure 2. Publicly accessible part of the Danish EPC Database (Screenshot). https://sparenergi.dk/ forbruger/vaerktoejer/find-dit-energimaerke.

\subsection{Databases Used for Populating the ENERFUND Tool}

All the databases used for uploading data on the ENERFUND tool were collected from the project partners through the competent authorities of each country. In Table 2, the database link per country, as was documented through the ENERFUND project, is shown. 
Table 2. Database per partner country for uploading data to the ENERFUND tool.

\begin{tabular}{|c|c|c|}
\hline Country & Database Link (If Available) & Notes \\
\hline Austria & N/A & EPC data are not public data in Austria. \\
\hline Bulgaria & N/A & Data export might be given in the form of files. \\
\hline Cyprus & N/A & N/A \\
\hline Denmark & $\begin{array}{l}\text { http://sparenergi.dk/forbruger/ } \\
\text { vaerktoejer/find-dit-energimaerke }\end{array}$ & $\begin{array}{l}\text { EPC data are public data in Denmark. They are available } \\
\text { by use of an internet link of Spar Energy. Raw data, } \\
\text { geodata included, is required by Netcompany. }\end{array}$ \\
\hline France & $\begin{array}{l}\text { https://www.data.gouv.fr/fr/ } \\
\text { datasets/base-des-diagnostics-de- } \\
\text { performance-energetique-dpe/ }\end{array}$ & $\begin{array}{l}\text { The dataset includes per EPC and for the domestic sector } \\
\text { only. For full database } \\
\text { http://www.observatoire-dpe.fr/index.php/statistique with } \\
\text { statistics easily accessible but aggregated to the } \\
\text { departments levels. } \\
\text { EPC database is available for Paris municipal buildings. }\end{array}$ \\
\hline Greece & $\begin{array}{l}\text { http://www.ypeka.gr/Default. } \\
\text { aspx?tabid=907\&language=el-GR }\end{array}$ & $\begin{array}{l}\text { Aggregated data for EPCs for geographical areas, decade } \\
\text { of construction, use, energy category, energy } \\
\text { consumption, etc. }\end{array}$ \\
\hline Ireland & $\begin{array}{l}\text { https: } \\
\text { //ndber.seai.ie/BERResearchTool/ } \\
\text { Register/Register.aspx }\end{array}$ & $\begin{array}{l}\text { Residential data only at the local level, not at the } \\
\text { building level } \\
\text { Non-residential data on the building level }\end{array}$ \\
\hline Romania & N/A & $\begin{array}{l}\text { Legal responsibility of the central EPC database is under } \\
\text { MDRAPFE, while the EPC in electronic format are } \\
\text { received and stored by NIRD URBAN-INCERC. The data } \\
\text { could be mapped if each EPC is geocoded } \\
\text { semi-automatically using the address. }\end{array}$ \\
\hline Slovakia & $\begin{array}{l}\text { http://www.inforeg.sk/ec/ } \\
\text { SearchEC.aspx }\end{array}$ & $\begin{array}{l}\text { Only in Slovak language. Geo-Data are contained in field } \\
\text { "Adresa budovy", where the text after the last comma } \\
\text { represents the name of the municipality. }\end{array}$ \\
\hline Slovenia & $\begin{array}{l}\text { http://www.energetika-portal.si/ } \\
\text { podrocja/energetika/energetske- } \\
\text { izkaznice-stavb/register- } \\
\text { energetskih-izkaznic/ }\end{array}$ & $\begin{array}{l}\text { Complete register of EPCs is publicly available in pdf only. } \\
\text { Single EPCs can be found on http://prostor3.gov.si/javni. }\end{array}$ \\
\hline Spain & $\begin{array}{l}\text { http://icaen.gencat.cat/es/energia/ } \\
\text { usos_energia/edificis/certificacio/ } \\
\text { registre_certificats/ } \\
\text { https://www.iderioja.larioja.org/ } \\
\text { vct/index.php?c= } \\
\text { 506a6a7670454c724c4772527a366c } \\
\text { 6c62666d3130673d3d\&t=5\&e1=A }\end{array}$ & Only two regions have maps of geo-referenced EPC. \\
\hline United Kingdom & $\begin{array}{l}\text { https: } \\
\text { //epc.opendatacommunities.org/ } \\
\text { https://www.ndepcregister.com/ }\end{array}$ & $\begin{array}{l}\text { Access to EPC data for buildings in England and Wales. } \\
\text { Non Domestic EPC register. }\end{array}$ \\
\hline
\end{tabular}

It is important to connect existing EPC databases with the ENERFUND tool to ensure availability of up-to-date information with moderate additional effort. Collection of EPC data just for the purpose of publicizing them through the ENERFUND tool causes high effort and thus is not a sustainable option in the long run.

\subsection{Processing of EPC Data for Display at the European Level}

Due to national differences in specifications of energy indicators, processing of EPC data was necessary to present information about energy performance in a comparable way all over Europe. To this end, qualitative scales with a range from very poor to very good were used to assess the energy performance of the walls, windows, roof, and the efficiency of the heating system, and to support in narrowing down areas of interest for deeper investigation. Different levels of public accessibility to EPC data in member states made it also necessary to create country specific websites operating at the country specific level of detail. Overall, approximately eight million unique EPCs were collected 
and are displayed on the website, with more than 80 million data sets used in the ENERFUND tool. In Figure 3, the variability in the quantity of data per country is shown.

\begin{tabular}{|c|c|c|c|c|c|c|c|c|c|c|c|}
\hline Country & $\begin{array}{l}\text { Current } \\
\text { rating }\end{array}$ & $\begin{array}{l}\text { Potential } \\
\text { rating }\end{array}$ & $\begin{array}{l}\text { ENER- } \\
\text { FUND } \\
\text { Score }\end{array}$ & $\begin{array}{l}\text { Walls } \\
\text { energy } \\
\text { eff. }\end{array}$ & $\begin{array}{l}\text { Windows } \\
\text { energy } \\
\text { eff. }\end{array}$ & $\begin{array}{l}\text { Roof } \\
\text { energy } \\
\text { eff. }\end{array}$ & $\begin{array}{c}\text { Main fuel } \\
\text { type } \\
\text { (heating) }\end{array}$ & Area $\left(m^{2}\right)$ & $\begin{array}{l}\text { Building } \\
\text { type }\end{array}$ & $\begin{array}{c}\text { Construction } \\
\text { year }\end{array}$ & $\begin{array}{l}\text { Aggregated } \\
\text { data }\end{array}$ \\
\hline $\mathrm{BG}$ & $\checkmark$ & $\checkmark$ & $\checkmark$ & $x$ & $x$ & $x$ & $x$ & $\checkmark$ & $\checkmark$ & $x$ & $x$ \\
\hline $\mathrm{CY}$ & $\checkmark$ & $x$ & $x$ & $x$ & $x$ & $x$ & $x$ & $\checkmark$ & $x$ & $\checkmark$ & $x$ \\
\hline DK & $\checkmark$ & $\checkmark$ & $\checkmark$ & $\checkmark$ & $\checkmark$ & $\checkmark$ & $x$ & $\checkmark$ & $\checkmark$ & $\checkmark$ & $x$ \\
\hline ES & $\checkmark$ & $x$ & $\checkmark$ & $x$ & $x$ & $x$ & $x$ & $\checkmark$ & $\checkmark$ & $x$ & $x$ \\
\hline $\mathrm{FR}$ & $\checkmark$ & $x$ & $x$ & $x$ & $x$ & $x$ & $x$ & $x$ & $\checkmark$ & $x$ & $\checkmark$ \\
\hline $\mathrm{GB}$ & $\checkmark$ & $\checkmark$ & $\checkmark$ & $\checkmark$ & $\checkmark$ & $\checkmark$ & $\checkmark$ & $\checkmark$ & $\checkmark$ & $\checkmark$ & $x$ \\
\hline $\mathrm{GR}$ & $\checkmark$ & $x$ & $\checkmark$ & $x$ & $x$ & $x$ & $x$ & $\checkmark$ & $\checkmark$ & $\checkmark$ & $x$ \\
\hline IE & $\checkmark$ & $\checkmark$ & $\checkmark$ & $\checkmark$ & $\checkmark$ & $\checkmark$ & $\checkmark$ & $\checkmark$ & $\checkmark$ & $\checkmark$ & $x$ \\
\hline IT & $\checkmark$ & $x$ & $x$ & $x$ & $x$ & $x$ & $x$ & $x$ & $x$ & $x$ & $x$ \\
\hline $\mathrm{NL}$ & $\checkmark$ & $x$ & $x$ & $x$ & $x$ & $x$ & $x$ & $x$ & $\checkmark$ & $x$ & $x$ \\
\hline RO & $\checkmark$ & $\checkmark$ & $x$ & $x$ & $x$ & $x$ & $x$ & $x$ & $x$ & $x$ & $\checkmark$ \\
\hline SI & $\checkmark$ & $x$ & $\checkmark$ & $x$ & $x$ & $x$ & $\checkmark$ & $\checkmark$ & $\checkmark$ & $\checkmark$ & $x$ \\
\hline SK & $\checkmark$ & $x$ & $\mathbf{x}$ & $x$ & $x$ & $x$ & $x$ & $x$ & $\checkmark$ & $x$ & $x$ \\
\hline
\end{tabular}

Figure 3. Type of data available per country.

\subsection{Results}

The EPC not only gives vital information concerning the energetic condition of a building, but the underlying calculations and technical documentations are also used to build up databases that have many benefits: Strategic inquiries (surveys, investigations), project developments, and statistical analyses. The spatial reference is thereby of central significance.

As part of the ENERFUND project, EPCs from 13 EU countries were made publicly available through GIS in order to provide information for the energetic improvement of the European building stock. However, the data available in the ENERFUND tool differ greatly depending on data availability at the national or regional level. While very large data sets for residential and non-residential buildings are published in Denmark and the UK, Ireland does not include residential data on the platform due to data protection concerns. For the Netherlands, only those data are available, which are to be displayed in real estate advertisements during the process of purchase or rent and are thus publicly available. In Spain, the range of data included in the ENERFUND tool is also very limited, but this is due to the regionally implemented and very different designed EPC databases, which resulted in the presentation of the lowest common denominator. In Cyprus, only a handful of EPCs with just the EPC rating are provided, while Austrian EPC data are not included in the ENERFUND tool at all. The interviews conducted with Austrian stakeholders in the project showed a rather negative attitude towards the public accessibility of spatially localized EPC data, mainly due to data protection concerns.

To summarize, the project team encountered three main challenges, the first two being in the sphere of influence of the EPBD, and the third one being in the sphere of influence of the GDPR:

1. Energy indicators included in the EPC differ: There are different specifications of energy indicators depending on the national or regional adaptations of the calculation method and other legal provisions at the member states' level.

2. Geolocation of data: Even though the address (i.e. postcode) of the building is specified in the EPC, the actual location of the building is often not connected to its address, thus external 
databases and/or methodologies are needed to match postcode to geolocation, resulting in huge delays in mapping the EPCs.

3. The level of detail of publicly available EPC data differs: There are various levels of detail regarding publicly accessible geo-referenced EPC data due to the range of interpretation regarding the term "identifiable", having resulted in different interpretations in member states.

\section{Data Protection Rules and Public EPC Data}

While populating the tool with EPC data it became evident that in some member states, such as Austria and Ireland, the range of interpretation of personal data according to GDPR poses a severe barrier with regard to making the ENERFUND tool functional in all member states. This chapter describes the procedure of analyzing the legal framework conditions with regard to data protection rules using the example of Austria. It explains the range of interpretation and its consequence and presents a suggestion on how to create the clarity needed to make tools like ENERFUND operational and useful for supporting EU's energy and climate policy.

\subsection{Analysis of Legal Barriers Related with Data Protection}

Based on the need for publicly available geo-referenced EPC on the one hand and uncertainty about the legal options on the other hand, it was examined to what extent data protection legislation applies and what the legal foundations in the field of Open Government Data (OGD) are. The analysis was based on the sources of information law and literature with the help of methodical instructions in the field of legal work techniques [25].

For the analysis of the personal relevance of EPC data, detailed research was carried out, among others, in legal databases and in the Curia database of the European Court of Justice (ECJ) on the topic of personal reference of geodata. Relevant literature was identified and evaluated, but no decisions of the ECJ with a direct relevance to the topic could be found and no guidelines or other documents on this topic were available from the Article 29 Working Group and its successor European Data Protection Board (EDPB). Therefore, the topic was further approached via the notion of the personal data for which comprehensive information is available [26], and the teleological interpretation of which priority is given to the objective problem in Ehmann/Selmayr [27]. Teleological argumentation is a method of interpreting the law based on the assertion that every legal provision has a goal and a purpose. As a basis for the teleological interpretation, the legal development in the field of energy efficiency and climate protection was also worked up in order to be able to grasp in particular the indefinite term "public interest". The framework conditions at the provincial level were exemplified in the Austrian provinces of Salzburg and Vienna [25].

\subsection{General Data Protection Regulation (GDPR) and Building Related Energy Data}

The public accessibility of EPC data clearly serves to realize energy policy goals, such as the development of long-term renovation strategies, aggregation of renovation projects to make use of economies of scale, and to plan activities addressing energy poverty. Yet, there has been uncertainty regarding the legal scope mainly for the identifiability of persons in the context of the GDPR, and this attitude has compromised the exploitation of the existing data pools.

The provisions of the GDPR refer to the protection of the basic civil rights of natural persons. According to recital 26 GDPR, the principles of data protection should apply to all information referring to an identified or identifiable natural person. Identifiability is defined in particular by reference to an identifier such as name, identification number, location data, or online identifier. They do not apply to anonymous information, meaning information not referring to an identified or identifiable natural person, or personal data that has been anonymized in a way that the affected person cannot or no longer be identified (pseudonymized data). However, in practice it is not always completely clear whether identifiability applies or not, and the address of residential buildings was found to be such a disputable case. 


\subsubsection{Are EPC Data Personal Data or Non-Personal Data?}

In Austria, the General Civil Code defines that everything that is different from a person and serves the personal use, is called a "thing" in the legal sense. Thus, a building is a physical, immovable thing [22], defined by technical aspects of the building materials and building technology systems as well as by its location because the location has an impact on the energy demand. The EPC contains building related general data such as area, year of construction, date of EPC issuance, and energy efficiency indicators, usually calculated applying standardized user profiles. These indicators are therefore not consumption values that could allow conclusions about the energy consuming person, but calculated values without any reference to the actual users of a building. General building information and calculated energy indicators are clearly non-personal EPC data because they describe the technical characteristics of a building. However, the EPC can also contain personal data, namely the name of the person who issued the EPC. With regard to the building address and the possible conclusions to its users in terms of the identifiability, buildings have to be differentiated depending on their type of use.

Address data of EPCs of buildings in the public sector on the municipal, federal, and state level, such as schools, kindergartens, and district offices are not affected by the GDPR because buildings are used by groups of people and thus can be considered anonymous data. Furthermore, there has been the legal obligation that EPCs must be displayed in public buildings, meaning that these EPCs are public already. Equally not affected are EPCs of office buildings or shops with other than residential usage, which are owned by legal persons. In these areas, no reference can be taken to the privacy of persons.

Thus, regarding the publication of geo-referenced EPC data, the stock of residential buildings needs to be looked at more closely to examine how to deal with addresses in the context of their public accessibility.

\subsubsection{Making a Difference: Building Address and Residential Address}

Geodata locates a place on the earth's surface with different methods, for example through the network of Gauss-Krüger coordinates or through addresses (city, street, and street number). The information contained in geodata has its origin in natural conditions and does not have to be generated by a special data collection and processing process. It is therefore information that is obvious and therefore generally accessible. Spatial data, including addresses, do not contain any personal data and are thus not relevant for data protection. However, records without personal reference can also be linked to people. With regard to the personal reference of geodata four categories can be distinguished:

- The localization of a person;

- The localization of a moveable item that can be assigned or assigned to a specific person;

- The indication of a place that a particular person regularly uses, in particular inhabited;

- The specification of a locality assigned to a person as the owner under civil law.

While the first two points refer to mobility behavior and are not relevant to the question dealt with here, the last two points concern the building area and thus the topic of this work.

The process relevant to data protection is the linking of space-related factual data with personal identification features, i.e., individual details about personal and factual circumstances of an identified or identifiable natural person.

While the building address documented in the EPC is linked with the building and not with the persons using the building, the residential address of a person is linked with the person's accommodation. In Austria, the personal data collected in the context of the mandatory registration is saved at the Central Resident Register [28]. The residential address is clearly a person-related data record, because it is the goal to find and identify a person based on the home address. In the case of residential buildings an identifiability of natural persons can occur by reference to the identifier location data, if the building address (non-personal data record) is identical with the residential address 
(personal data record) according to the Central Resident Register. However, the EPC database and the Central Resident Register are two different databases, and there is no factual necessity to process and combine personal data of the resident register or further personal data with technical building related energy data for the mere public representation of geo-referenced EPC data. Yet, the fact that an authority has access to both, the EPC database and the Central Resident Register, can be considered sufficient that processing must take place under the provisions of the GDPR.

The term "identifiable" includes quite some range of interpretation, and when a person is identifiable, there is some controversy between supporters of an absolute and a relative interpretive approach. According to the absolute theory (also called objective theory), the theoretical possibility of identifying a person based on the data, be it by the responsible body or by a third party, is sufficient. In fact this means that a person is always identifiable, at least indirectly, and therefore an address is always personal data, especially when taking into account the rapidly evolving technical possibilities. In contrast to the absolute theory, the relative theory relies on the knowledge of the responsible body and on the means actually available to obtain the necessary information at a reasonable cost. This does not mean that this also has to be practically the case, but only that the possibility is given at a reasonable cost.

The application of the absolute theory to the data set "building address" would lead to a ubiquitous personal reference, since each property has an owner and users, and in view of the existing and evolving technical possibilities a conclusion on the personal circumstances would be eventually possible. The absolute interpretation precludes many useful approaches to tap the full potential of data pools, such as the publication of geo-referenced residential EPCs on the ENERFUND tool, in order to facilitate deep renovations in buildings. In this regard, it is essential to remember the purpose of the GDPR: The regulation is not about data protection as such but about the protection of personal rights. Looking at personal rights, the question emerges which personal rights will be at stake if the building energy performance is published together with the address of a residential building. Based on this, it is inferred that the building address of residential buildings may be a non-personal record or a personal record, depending on the context. The following example illustrates the boundary between the building address as a non-personal date and a personal date:

"The value of a particular house is information about an object. Data protection rules will clearly not apply when this information will be used solely to illustrate the level of real estate prices in a certain district. However, under certain circumstances such information should also be considered as personal data. Indeed, the house is the asset of an owner, which will hence be used to determine the extent of this person's obligation to pay some taxes, for instance. In this context, it will be indisputable that such information should be considered as personal data." [26].

If one applies this example to the objective question, the description could be as follows: The energy demand, the year of construction, and the energy efficiency of components are information about an object. Privacy policy does not apply if the building address is used to illustrate energy-related characteristics in a particular area. In certain circumstances, however, this information is also in the category "personal data", namely when combined with socio-demographic data and central register data, in order to make decisions in the field of energy spatial planning or promotion.

Damm [17] (p. 370) shows that this proposal corresponds to that of the Commission Law and Geodata of the German Cartographic Society. Accordingly, geodata and their identification features such as coordinates, house numbers, or parcel numbers are personal data only if they are associated with other individual identification features, in particular with name, passport number, identity card number, social security number, or tax number.

\subsubsection{Distinguishing Between Processing and Disclosure of Data}

In Austria, the conclusion was that a distinction has to be made between the public accessibility of building addresses and energy characteristics per se, and the processing of data by an authority: 
- Public accessibility of geo-referenced EPC data: There is no reference to persons within the meaning of the GDPR. If a third person has access to the geo-referenced technical building characteristics, it is theoretically possible to establish a personal reference to buildings by querying the Land Register, since the owners are recorded in the Land Register. However, this is associated with considerable effort, since the queries must be entered individually and a general automated query is not possible without legitimate interest. Each person also has the right to request registration information from the registration authorities about the principal place of residence of another person. The goal of the request, however, is to determine the address of a person and not which persons are registered at an address.

- Data processing by an authority to make the EPC data available in a geo-referenced way: If this is an authority with access to the Central Resident Register, then, according to relative theory, it is possible to establish a personal reference.

In summary, it can therefore be assumed that the geo-referenced public representation of technical building data of the EPC does not have any personal relevance for residential buildings either. Yet, processing of data to make them accessible can be within the scope of the GDPR.

If names, registration addresses, and income data are linked to the energy characteristics of buildings in order to implement targeted promotion instruments for energy efficiency measures or to tackle energy poverty, then the provisions for the lawfulness of data processing according to GDPR clearly apply.

\subsubsection{Lawfulness of Processing Personal Data and Opening Clauses}

Data processing within the scope of the GDPR can only take place under certain conditions, which legally allow the processing of personal data, as set out in Article 6(1) GDPR within three categories:

- The person concerned gives his/her consent to process personal data for one or more purposes (point a);

- Data processing is necessary to protect vital interests of the persons concerned or other natural persons (point d);

- The processing of personal data is required due to specific factors, such as the performance of a contract, compliance with a legal obligation, the performance of a task carried out in the public interest and in the exercise of official authority vested in the controller, or to protect interests of responsible persons or third parties (point $b, c, e$, and f).

Article 6 GDPR contains so-called opening clauses, among others in paragraph 1 point $c$ and point e. Opening clauses allow a specification of the legal grounds, but only within the prescribed limits, in order to be able to respond to national circumstances.

The requirements of the first and the third category mentioned above are relevant to the subject matter and are therefore analyzed in more detail in the following paragraphs.

Consent of the person concerned (point a): The consent of the person concerned can be active and passive, through the declaration of the consent for the publication of data, or through the request to remove their own published data. With reference to the EPC both variants would involve high administrational effort and seem hardly appropriate to achieve nationwide publicly accessible EPC data, in particular for the building stock.

Compliance with a legal obligation (point c): In the Austrian provinces analyzed for this project, there is the legal obligation to control EPCs according to Article 18 EPBD, and for this purpose, personal data of EPC experts may be processed. Only non-personal EPC data may be used for other purposes than the independent control system. This is the reason why it is necessary to categorize the address of residential buildings as either personal or non-personal data. In Austria, opening clauses were not used to clarify certain conditions such as how to deal with the address of residential buildings. In Austria, data protection is a complex legal matter in general because many specific data protection 
provisions are part of a great number of specific administrative laws and it is hard to maintain the overview regarding their impact.

Public interest (point e): The public interest exists in the added benefit, which is offered by EPC databases beyond the establishment of an independent control system according to Article 18 EPBD, and is based on the goals and objectives of the Energy Union. In order to achieve the goals of the Energy Union, there certainly exists a public interest in information concerning the location of buildings with poor energy efficiency. The localization of a building is the key to the geo-referenced presentation of EPC data, which facilitate the development of energy efficiency projects, sensitize the population for issues of energy efficiency and $\mathrm{CO}_{2}$ reduction, and allows a comparison with neighboring buildings, thus enabling market dynamics. Thus, public interest should be sufficiently justified by the intention of the EPBD as well as by the Energy Union's goals. In the case of a given public interest, the consent of a person concerned for legal processing is not required anymore, but the data subject has the right to object at any time to processing of personal data concerning him or her. In this case, according to Article 21(1) GDPR, the controller shall no longer process the personal data unless the controller demonstrates compelling legitimate grounds for the processing that override the interests, rights, and freedoms of the data subject. However, "public interest" is an abstract legal term, which can be interpreted in different ways and has to be weighed against personal interest. In Austria, there is no tradition and no accepted tools to do so [29], which makes it difficult to refer to "public interest" as the justification for the lawfulness of data processing. Opening clauses were not used to clarify the term "public interest". For this reason a legal uncertainty is given, which in practice constitutes a barrier to the public accessibility of geo-referenced EPC data.

Legitimate interests pursued by the controller or by a third party (point $\mathrm{f}$ ): There is a legitimate interest of Energy Service Companies and companies offering products to improve energy efficiency of buildings to contact the owners of buildings with bad energy performance. There is the exception where such interests are overridden by the interests or fundamental rights and freedoms of the data subject, which require protection of personal data, in particular where the data subject is a child. This is not the case in the subject matter. However, concerned persons have the right to object at any time to processing of personal data concerning him or her according to Article 21(1) GDPR.

\subsection{Is Energy Efficiency and $\mathrm{CO}_{2}$ Reduction a Task Carried Out in the Public Interest?}

In the Treaty of Lisbon in 2007 the title "energy" became an explicit component of the EU Primary Law. Thereby a stronger legislative basis for related legal acts affecting the member states exist than it was previously the case on the basis of the title "environment" (registered in the course of the Treaty of Maastricht 1992). The high importance is being expressed in the establishment of the Energy Union and is also apparent in the significantly increasing detailing and concretization of building related energy efficiency provisions of Directives 93/76/EWG, 2002/91/EU, 2010/31/EU and amending Directive (EU) 2018/844. However, in practice, the lack of energy efficiency of the building stock remains a major challenge because the required rate of refurbishment of $3 \%$ for the improvement of energy efficiency of the building stock could by far not be reached despite of strenuous efforts. This demonstrates that since the Maastricht Treaty, the issues of energy efficiency and climate change have steadily strengthened their importance and that there certainly is public interest in actions such as public accessibility of geo-referenced EPC data, which will help meeting the obligations.

However, chapter 1.2.2. shows, that in comparison with the importance of the protection of personal rights, energy efficiency and climate protection still have to be classified as secondary, if the rights to privacy worth protecting according to the Convention for the Protection of Human Rights and Fundamental Freedoms and the Charter of Fundamental Rights of the European Union are concerned. Protection of personal rights is of high importance but has to be weighed against the rights of the public to make informed decisions in environmentally relevant areas. Therefore, the focus of analysis was on rights worth to protect, resulting in the conclusion that the publicly available presentation of geo-referenced EPC data does not affect such a privacy right, whereas the public clearly benefits from 
such a representation, namely through investments in building renovations with environmental and economic benefits.

\section{Discussion}

This chapter discusses results presented in chapter 2 and 3, highlighting the aspects most important.

\subsection{ENERFUND Tool Provides Public Access of EPC Data to Support EU's Climate and Energy Policy}

It is an important goal of the EU's Climate and Energy Policy to improve the energy efficiency of the European building stock and to reduce $\mathrm{CO}_{2}$ emissions. Data is needed for informed decision making and to identify cost efficient large-scale building renovation projects. Due to the issuing of EPCs since more than 20 years ago, there has been the opportunity to build a data pool on the building stock, which should now be made accessible to be useful for identifying areas for large-scale renovations, for developing new products and services, and for energy spatial planning with a focus on exploiting renewable energy potentials. The ENERFUND tool builds on the availability of EPC data and has developed an approach how to present building related energy data at the European level by means of a geographical information system. Although the tool could be successfully established, it became evident that further harmonization of EPBD provisions is needed to enable the effective exploitation of existing data pools (see also [30])

The range of approaches how member states implement the EPBD is very wide and poses a challenge to developing tools making use of EPC data at the European level. However, EPC data can also be made available by means of GIS at the national and regional level as demonstrated by the Danish case.

\subsection{Public Access of Data to Support EU's Climate and Energy Policy Verus Personal Rights Protection}

The EU has been promoting public accessibility of data for the promotion of environmental awareness, innovation, and competitiveness, the development of new products and services and, more generally, the quality of decision-making for many years. Development began with the first Environmental Information Directive in the early 1990s, continued with the INSPIRE Directive in 2007 and the PSI Directive, which has been a revised draft since 2018, in order to better address the challenges of digitization.

On the one hand, this gives citizens the right to access data, but on the other hand, it also limits this right, for example if it concerns security-relevant data or personal data. The personal reference is given through identification or identifiability by means of certain parameters, such as location data, among other the address.

\subsection{Building Address Can Be Contextually Assigned as Personal or Non-Personal Data}

With regard to public accessibility of geo-referenced EPC data it is shown that the building address can be contextually assigned as personal or non-personal data especially in the residential sector.

Generally speaking, information refers to a person when it comes to information about that person, but the technical data contained in the EPC relates to an object, namely the building, and not to the person who owns the building. However, the building may be subject to a certain influence by persons and may have a spatial proximity to persons. Depending on the context, the building address can be non-personal or personal data: For example, privacy policy does not apply if information is used solely to illustrate real estate prices in a particular residential area. However, the property is an asset, which is used inter alia to determine the taxes payable by the owner. In this context, the personal relevance of this information is undeniable.

Residential buildings represent by far the largest share of the building stock and therefore their geo-referenced EPC data should be included in geographical information systems to support planning for the long-term renovation strategy and innovation in the product and service sectors. This range of interpretation concerning personal data creates uncertainty and hesitant or no decision-making how to 
tackle public access to geo-referenced EPC data. When classifying as personal data, the conditions governing the lawfulness of data processing under the GDPR are applicable, according to which a legal ground or a public or legitimate interest in processing must be present. It is shown that at least the conditions public and legitimate interest apply to the objective question, but it is also clear that information classified non-personal data are certainly easier to handle.

\subsection{Solving the Problem by Referring to the Intention of the Legislator}

The range of interpretation mentioned above is expressed by two different possible ways of interpretation, namely the absolute and relative theory. The application of the absolute theory to the data set "building address" would lead to a ubiquitous personal reference, since each property has an owner and in view of the existing technical possibilities a conclusion on the personal circumstances would always be possible. With the building address, however, the question arises as to which personality right should be protected, especially since building addresses represent generally accessible and perceptible information, and this representation does not affect the privacy of natural persons. It should therefore be borne in mind that the European legislator intentionally broadcasts the concept of "personal data" in order to ensure the protection of personal rights as comprehensively as possible and with a high degree of flexibility. However, an excessively restrictive interpretation of the definition of personal data is not intended to ensure the protection of the rights of individuals and the legitimate interests at the same time.

For buildings with poor energy efficiency, the address-related representation of energy characteristics could be interpreted as an invasion of the privacy of those who own the building, because high energy demand indicates outdated technical building quality, which (depending on the location as the most important factor for the property value) in average locations can certainly affect the value of a property. However, it can be argued that this is exactly the intention of the EPBD: Real estate should be made comparable in terms of its energy quality to increase the demand for buildings with good energy labels. For this reason, the EPC for a specific building must be submitted for sale or rental, or selected characteristics must be shown in the real estate advertisements. Based on the consideration of the interests involved, the above interpretation is therefore considered inadmissible.

\section{Conclusions}

Based on the material presented in this article, it is concluded that the publicly available presentation of spatially located EPC data is also justified in residential buildings, because the right of the public to information must be balanced with the right to privacy and the inviolability of the home. The geo-referenced representation of building-related energy data does not affect the privacy and inviolability of the home, but it does make it possible to take better decisions in the interest of the general public. This is especially important because residential buildings represent the major share of the building stock, for example this is around 90\% in Austria [31]. However, the discussion also underlines the challenges associated with context dependent interpretation of personal data regarding the residential building address. This legal uncertainty hinders the ENERFUND approach. Therefore, an official guidance note at the EU level will be needed, in order to clarify unambiguously the context in which geo-referenced EPC data can be regarded non-personal data, in order to facilitate decision-making at the authority and stakeholder level to actually make EPC data publicly accessible.

The Irish experience strongly confirms this need: The residential EPC dataset in Ireland has been managed and maintained by the Sustainable Energy Authority of Ireland (SEAI). In Ireland, there is an ongoing debate with SEAI for more than 21 months in trying to resolve GDPR issues regarding access to residential EPC data via online retrofit tools and/or presenting residential EPC data at the building level. The debate has often seemed to go around in circles. This has not been helped by different persons being introduced to the discussions over time and personnel changes amongst SEAI's legal advisers, hence new people have to be re-briefed and often earlier advances can get lost along the way. SEAI has also advised that formal advice to them from the Irish Data Protection Commissioner's Office 
has varied sometimes from month to month, leading to uncertainty. It seems that the biggest challenge is a nervousness about the potential legal exposure for breaching GDPR and hence the legal advice is unexpectedly extremely cautious. An official EU guidance note would be a huge assistance both in Ireland and EU wide to all parties.

These conclusions result in the recommendations to ensure public accessibility of geo-referenced EPC data presented in the subchapters below.

\subsection{Clarification of Context: EPC Data As Non-Personal Data}

At the EU level, it would be useful to have a guidance note from the European Commission that supports the interpretation of building related EPC data as non-personal data, thus falling within the scope of the INSPIRE Directive and, in particular, refers to the issue of address of residential buildings. The guidance note would have to be drawn up by DG ENER responsible for the EPBD in consultation with the European Data Protection Board, whose founding is enshrined in the GDPR and whose task it is to provide guidelines for the interpretation of the GDPR. Pursuant to Article 70(1) point (e) of the GDPR, the European Data Protection Board may both on its own initiative and at the request of the European Commission, issue guidelines and recommendations, including regulatory examples, to guide those responsible, data subjects, and supervisors.

The following proposal could serve as a starting point for developing such a guidance note: The year of construction, the type of building use, the calculated energy demand, the type of energy carrier, the energy efficiency of components (envelope and heating system), the presence of solar technologies (thermal modules and photovoltaic modules), and location data for geo-referenced presentation are information about an object. Data fields should be exactly specified to create uniform conditions and comparable results across Europe, and to allow for automatic geocoding. With regard to the building address, privacy policy does not apply if the building address is used to illustrate energy-related information and characteristics about the building in a particular area. This applies to all building types for which an EPC is foreseen, including residential buildings of the single-family type. Under certain circumstances, however, this information can also be considered as a "personal data" category, when combined with information about identified persons, in order to develop and/or apply targeted energy and climate policy tools.

This approach would take into account the growing importance of energy and climate policies and would not contradict the EU's guiding principle of subsidiarity and proportionality. The repeated request that the EPBD should be enacted as a European regulation instead of a European directive and that elements such as the EPC database should be made mandatory with defined data fields is understandable and even justifiable on the basis of the evaluation of the implementation of the EPBD, but is currently not supported by the majority.

\subsection{Data Source: Independent Control System According to Article 18 EPBD}

The independent control system in the context of article 18 EPBD refers to all EPCs, which are issued under the building law as well as in the course of sale and rental, and display for public buildings. If the control system is based on an electronic database, an interface can be easily created to display selected geo-referenced energy data on a map, provided there is clarification concerning classification of the building address as non-personal data. If there is no clarification, residential data will have to undergo anonymization whereby different opinions exist concerning the conditions necessary to impede conclusions to a person. There is a range of interpretation resulting in discussions and the tendency to avoid decisions due to legal uncertainty and increasing administrative burden.

Nevertheless, the independent control system according to article 18 EPBD is considered to be a promising starting point for the public accessibility of geo-referenced EPC data in order to support the member states in achieving the goals of the Energy Union. 


\subsection{Method of Presentation: Digital Cadastral Map}

The INSPIRE Directive provides for the geographical information systems needed to display geo-referenced EPC data. In Austria, the Digital Cadastral Map (cadastre) is open data and publicly accessible to show certain land conditions based on the Survey Act [32]. The Cadastral Map together with the Land Register (contains also information about owners) forms the Land-Register Database. The database can be accessed for targeted queries against a fee.

Components of the Austrian cadastre are principally technical records, a list of properties, and an address register, which contains all geo-coded addresses fed in by the responsible communities and being identical with the Building and Housing Register of Statistics Austria. These digital data contains the presentation of physiographic potentials, such as the potential for renewable energy sources, and is available at the Austrian Federal Office for Metrology and Surveying. Geographical information systems (GIS), which contain the digital cadastral map and further information, are available in the Austrian Provinces (such as SAGIS in Salzburg, ViennaGIS in Vienna). At the regional level, it should be possible with very little effort to integrate the Provinces' EPC databases into their GIS, once clarification is available how to deal with residential addresses in the context of energy efficiency and $\mathrm{CO}_{2}$ reduction.

In conclusion, it is stated that electronic data availability and data reuse opportunities offer great potential for optimizations and new developments, but pose a major challenge at the same time because of limited manpower available in the administration. Here, applied research can support the development of robust tools and processes to generate the maximum benefit as simply as possible and with the least possible effort. Recognized models for balancing the public interest in information and those personal rights that are worthy of protection would be helpful in Austria and maybe in other countries, as well. In this regard, also, further work is considered necessary.

The sole responsibility for the content of this publication lies with the authors. It does not necessarily reflect the opinion of the European Union. Neither the EASME nor the European Commission are responsible for any use that may be made of the information contained therein.

Author Contributions: Legal analysis, conceptualization and original draft preparation, S.G.; review of article and input on ENERFUND tool, A.G.C.; review of article and input on Irish case, M.H.

Funding: ENERFUND has received funding from the European Union's Horizon 2020 programme under Grant Agreement No 695873.

Conflicts of Interest: The authors declare no conflict of interest. The funders had no role in the design of the study; in the collection, analyses, or interpretation of data; in the writing of the manuscript, or in the decision to publish the results.

\section{References}

1. Directive (EU) 2018/844 of the European Parliament and of the Council of 30 May 2018 amending Directive 2010/31/EU on the energy performance of buildings and Directive 2012/27/EU on energy efficiency (Text with EEA relevance). Off. J. Eur. Union L 2018, 156, 75.

2. Paris Agreement. Off. J. Eur. Union L 2016, 282, 4.

3. European Commission. Building the Energy Union. Available online: https:/ec.europa.eu/energy/en/topics/ energy-strategy-and-energy-union/building-energy-union (accessed on 14 April 2019).

4. Directive 2010/31/EU of the European Parliament and of the Council of 19 May 2010 on the energy performance of buildings (recast). Off. J. Eur. Union L 2010, 153, 13-35.

5. Council Directive 93/76/EEC of 13 September 1993 to limit carbon dioxide emissions by improving energy efficiency (SAVE). Off. J. Eur. Communities L 1993, 237, 28-30.

6. Directive 2002/91/EC of the European Parliament and of the Council of 16 December 2002 on the energy performance of buildings. Off. J. Eur. Communities L 2003, 1, 65.

7. Geissler, S.; Altmann, N. CT1 Thematic Report-How to Make the Best Use of EPCs. 2015. Available online: https:/www.epbd-ca.eu/wp-content/uploads/2011/05/CA-EPBD-How-to-make-use-ofEPCs.pdf (accessed on 17 April 2019). 
8. The ENERFUND Project: An ENERgy Retrofit FUNDing Rating Tool. Available online: http://enerfund.eu/ (accessed on 14 April 2019).

9. Regulation (EU) 2016/679 of the European Parliament and of the Council of 27 April 2016 on the protection of natural persons with regard to the processing of personal data and on the free movement of such data, and repealing Directive 95/46/EC (General Data Protection Regulation). Off. J. Eur. Union L 2016, 119, 1-88, (Text with EEA relevance).

10. Directive 2003/4/EC of the European Parliament and of the Council of 28 January 2003 on public access to environmental information and repealing Council Directive 90/313/EEC. Off. J. Eur. Union L 2003, 41, 26-32.

11. Directive 2007/2/EC of the European Parliament and of the Council of 14 March 2007 establishing an Infrastructure for Spatial Information in the European Community (INSPIRE). Off. J. Eur. Union L 2007, 108, 1-14.

12. Directive 2003/98/EC of the European Parliament and of the Council of 17 November 2003 on the re-use of public sector information, Official Journal of the European Union L 2003/345, 90 as amended by Directive 2013/37/EU of the European Parliament and of the Council of 26 June 2013 amending Directive 2003/98/EC on the re-use of public sector information (Text with EEA relevance). Off. J. Eur. Union L 2013, 175, 1.

13. Council Directive of 7 June 1990 on the freedom of access to information on the environment (90/313/EEC). Off. J. Eur. Communities L 1990, 158, 56-58.

14. Gesetz über den Zugang zu Informationen über die Umwelt LGBl für Wien 2001/15 idF LGBl für Wien 2018/62. Wiener Umweltinformationsgesetz-Wr. UIG. Available online: https:/www.ris.bka.gv.at/GeltendeFassung. wxe? Abfrage=LrW\&Gesetzesnummer=20000201 (accessed on 17 April 2019).

15. Wiener Stadtentwicklungs-, Stadtplanungs- und Baugesetzbuch, LGBl für Wien 1930/11 idF LGBl für Wien 2018/37, § 2a Abs 3 Z 1 und 2. Bauordnung für Wien - BO für Wien. Available online: https://www.ris.bka.gv. at/GeltendeFassung.wxe? Abfrage=LrW\&Gesetzesnummer=20000006 (accessed on 17 April 2019).

16. The Nine Provinces of Austria. Available online: http://www.geoland.at/ (accessed on 14 April 2019).

17. Damm, M. Der Zugang zu staatlichen Geodaten als Element der Daseinsvorsorge; Duncker \& Humblot: Berlin, Germany, 2017; ISBN 9783428150960.

18. Klessmann, J.; Denker, P.; Schieferdecker, I.; Schulz, S.E. Open Government Data Deutschland. Eine Studie zu Open Government in Deutschland im Auftrag des Bundesministerium des Innern. 2012. Available online: https://www.verwaltung-innovativ.de/SharedDocs/Publikationen/eGovernment/open_ government_data_deutschland_langfassung.pdf?_blob=publicationFile\&v=5 (accessed on 29 December 2018).

19. Directive 95/46/EC of the European Parliament and of the Council of 24 October 1995 on the protection of individuals with regard to the processing of personal data and on the free movement of such data. Off. J. Eur. Communities L 1995, 281, 31.

20. Convention for the Protection of Human Rights and Fundamental Freedoms, Rome, 4.XI.1950. Available online: https://www.echr.coe.int/Documents/Convention_ENG.pdf (accessed on 14 April 2019).

21. Charter of Fundamental Rights of the European Union (2012/C 326/02). Off. J. Eur. Union C 2012, $326,391$.

22. Thing, § 285 ABGB, § 2297 ABGB, JGS No. 946/1811. Available online: https://www.ris.bka.gv.at/ GeltendeFassung.wxe?Abfrage=Bundesnormen\&Gesetzesnummer=10001622 (accessed on 14 April 2019).

23. Right to privacy, § 1328a ABGB, JGS No. 946/1811. Available online: https://www.ris.bka.gv.at/ GeltendeFassung.wxe?Abfrage=Bundesnormen\&Gesetzesnummer=10001622 (accessed on 14 April 2019).

24. Geissler, S.; Androutsopoulos, A.; Charalambides, A.G.; Jareño Escudero, C.; Jensen, O.M.; Kyriacou, O.; Petran, H. ENERFUND-Identifying and rating deep renovation opportunities. In Proceedings of the Manuscript submitted to SBE Graz Conference, Graz, Austria, 11-14 September 2019.

25. Geissler, S. Öffentliche Zugänglichkeit von gebäudebezogenen Energiedaten. Master's Thesis, Donau-Universität, Krems, Austria, 2019.

26. Article 29 Data Protection Working Party. Opinion 4/2007 on the Concept of Personal Data. 01248/07/EN WP 136. Adopted on 20th June. Available online: https:/ec.europa.eu/justice/article-29/documentation/opinionrecommendation/files/2007/wp136_en.pdf (accessed on 15 April 2019).

27. Ehmann, E.; Selmayr, M. Einführung. In DS-GVO: Datenschutz-Grundverordnung: Kommentar, 2. Auflage; Ehmann, E., Selmayr, M., Albrecht, J.P., Baumgartner, U., Bertermann, N., Beck, C.H., Eds.; LexisNexis: München, Wien, Gemany, 2018; pp. 91-148. ISBN 9783406720062. 
28. Bundesgesetz über das polizeiliche Meldewesen BGBl 1992/9 idF BGBl I 2018/56. Meldegesetz 1991-MeldeG. Available online: https:/www.ris.bka.gv.at/GeltendeFassung.wxe?Abfrage=Bundesnormen\& Gesetzesnummer=10005799 (accessed on 17 April 2019).

29. Pirc Musar, N. Access to Public Information Versus Protection of Personal Data. How to Strike the Right Balance Using A Public Interest Test; NWV: Wien, Austria, 2018; ISBN 978-3-7083-1213-2.

30. Pignatelli, F.; Martirano, G. INSPIRE Harmonisation of existing Energy Performance Certificate datasets. In European Union Location Framework Energy Pilot; Publications Office: Luxembourg, 2016; ISBN 978-92-79-64461-0.

31. Statistik Austria. Gebäude und Wohnungen 2011 nach Art des (Wohn-)Gebäudes und politischen Bezirken. Available online: http://www.statistik.at/web_de/statistiken/menschen_und_gesellschaft/wohnen/ wohnungs_und_gebaeudebestand/index.html (accessed on 15 April 2019).

32. Bundesgesetz vom 3. Juli 1968 über die Landesvermessung und den Grenzkataster BGBl 1968/306 idF BGBl 2016/51. Vermessungsgesetz-VermG. Available online: https://www.ris.bka.gv.at/GeltendeFassung.wxe? Abfrage=Bundesnormen\&Gesetzesnummer=10011400 (accessed on 17 April 2019).

(C) 2019 by the authors. Licensee MDPI, Basel, Switzerland. This article is an open access article distributed under the terms and conditions of the Creative Commons Attribution (CC BY) license (http://creativecommons.org/licenses/by/4.0/). 